\title{
Why institutional delivery is still the last option to rural women in North West Ethiopia: Qualitative study
}

Netsanet Fentahun Babbel ( $\nabla$ netsanetfentahun01@gmail.com )

Bahir Dar University

\section{Wubegzier Mekonnen}

Addis Ababa University School of Public Health

Yosef Wasihun

Bahir Dar University

Mulunesh Alemayehu

Bahir Dar University

Research article

Keywords: Ankasha Guagussa, facility childbirth, home delivery, qualitative

Posted Date: November 25th, 2019

DOI: https://doi.org/10.21203/rs.2.17654/v1

License: (c) (i) This work is licensed under a Creative Commons Attribution 4.0 International License.

Read Full License 


\section{Abstract}

Background: whatever the actions has been implemented, home delivery preference in Ethiopia is still over $72 \%$. To date, no studies explored why institutional delivery is still the last option to rural women in Ethiopia. This study was conducted to explore the reason why institutional delivery is still the last option to rural women in Awi Zone Northwest Ethiopia.

Methods: An explanatory qualitative study was conducted from February to March 2014. Participants were selected purposively and written informed consent was sought. Twelve reproductive aged females, ten religious and twelve community leaders and sixteen key informants were participated. Data were collected by using semi-structured questionnaire using focused group discussion and in-depth interview guides. Thick description and peer debriefing were applied to assure data quality. Thematic analysis framework was used to analyse the data.

Results: The study revealed that institutional delivery is still the last option to the study area. Individual related factors like information gap, low risk Perception to pregnancy and delivery have been mentioned as drive factors for not using institutional delivery. Community related factors of women's poor position to decision, beliefs and cultural practices for home delivery preference affects institutional delivery. In addition, health facility related barriers like inaccessibility of health facility, infrastructure, lack of privacy during delivery, misconducts of health care providers and high risk perception to health facility delivery were repeated raised as reasons of last option of institutional delivery.

Conclusion: This study elucidated that home delivery preference was existed, given high social and cultural price for home delivery and misconceptions towards institutional delivery. Thus, the Ethiopian government together with its partners should focus on accessing health facilities, infrastructure, equipping health facilities with essential materials and skilled health professionals and increasing knowledge of the community, avert communities' misconceptions and deep-rooted socio-cultural beliefs towards institutional delivery.

\section{Background}

Globally, 216 women are still dying from pregnancy and delivery related complications in a day[1]. More than $70 \%$ of deaths are due to post-partum haemorrhage, infection, unsafe abortion; pregnancy induced hypertensive and obstructed labour complications. More than $75 \%$ of maternal deaths are occurred during postnatal period and more than half deaths take place within 24 hours of delivery[2]. Except pregnant induced hypertension, all major causes of deaths are easily avoidable and $99 \%$ of the event has been in the developing countries $[3,4]$.

Maternal death could be prevented more than 75\%, if skill care during childbirth [5]. Yet, in Ethiopia majority of mothers are not beneficiary in use of health facility where skilled birth attendants and adequate supplies are guarantee of quality care [6]. 
The worst thing in this area was few women give birth inside or outside their home by do it themselves [610]. According to EDHS 2016, maternal death ratio was 412 and institutional delivery was $28 \%$ in Ethiopia. [11-14]. The government of Ethiopia in collaboration with its partners has been still striving in implementing the road maps which are vital for the well-being of mother and new-born however, the result is still far due to different un noticed reasons $[14,18,19]$.

Therefore, this study was very important as it has additional intentions of reflecting root causes of low use of skilled birth attendants, thereby suggesting potential remedies for programme planners, policymakers and other responsible bodies for intervention. Moreover, the study design of qualitative nature is better measuring the individual and community perspectives, misconceptions, sensitive issues and cultures of rural Ethiopia adding to its creditability $[7,16,17]$

\section{Methods And Materials}

\section{Study design and setting}

Qualitative study was conducted in Ankasha Guagussa district of Awi zone from February to March, 2014 which is $463 \mathrm{~km}$ far from Addis Ababa. The study area was known as low institutional delivery utilization (18\%) [6]. According to 2007 census, the total population of the district is expected to be 221,796 with an area of $79,881 \mathrm{~km}^{2}$. The population were Agew in ethnic origin and speak both Agewugna and Amharic languages. Agricultural products such as Maize, Teff, Red pepper, wheat ..., were the main source of income for the community [6].

\section{Study participants and sampling technique}

Overall, 34 individuals participated in the three FGDs: FGD-1 comprised of 10 religious leaders, FGD-2 comprised of 12 community leaders and FGD-3 comprised of 12 reproductive-aged females. In addition, 16 key informant's interviews were conducted. For this study, Health Care Providers other than health extension workers labelled as $\mathrm{KI}-1$; health extension workers labelled as $\mathrm{KI}-2$ and Informal participants labelled as $\mathrm{KI}-3$. Purposively sampling techniques were used to select participants.

\section{Data collection methods and tools}

FGD and IDI were the data collection methods. Semi structured FGD guide and key informant interview guide was used for collecting the data. FGD and IDI guides were developed firstly in English and translated in to Amharic to collect the data and then translated back to English to check reliability. During discussion, codes was given to each participants and profile was registered. A principal investigator moderated each discussion. One note taker was assigned for each interview. Each participant was encouraged to talk and control participants' dominance during focus group discussion. All discussions and interviews were digitally tape-recorded. All FGDs and individual depth interview were conducted in a place free from disturbance. 


\section{Data analysis}

Data analysis was done side by side of the data collection. For all independently recorded FGDs and indepth interviews, data were transcribed word by word at each step after a repeated listening. The transcripts were cross checked with recordings. Transcribed data were coded in to related themes and sub-themes. verbatim quotations are used to show their responses to vital issues and themes.

\section{Trustworthiness}

Developed data collection tools were pretested in similar context. Thick description during analysis were considered as data quality measurements and assuring trustworthiness of the data. Throughout the study, bracketing of preconceptions of the investigator was employed. The emerging findings during analysis were shared to experienced qualitative researchers for peer debriefing before synthesizing the final outputs.

\section{Ethical considerations}

Ethical approval was obtained from the Research Ethics Committee of the School of Public Health, Addis Ababa University, and support letter was obtained from the District Management Council. The purpose of the study was explained to all participants and the study was begun after obtaining verbal consent. They were assured their anonymity and privacy and informed that they can discontinue at any time.

\section{Results}

Characteristics of the participants

The study participant mean age was 39.8 year. Out of 34 focused group discussion participants, 8 female participants were illiterate and 15 participants were can read and write (Table-1).

Out of 16 individual depth interview participants; 10 participants were health care providers and 6 informal participants who came at Health facility for scheduled child immunization and family planning. More than three quarter of in-depth interviewees were found on mean age of 29 (Table-2).

\section{Institutional delivery Practices and Barriers}

The study revealed various reasons that favour home delivery to be first in the selected district. The three main themes: the individual, community and facility factors were come out to show how the pregnant women is affected to use skilled birth attendants and quality of health care. Theme-10 Individual factors

\section{Category-1: Information gap}

Illiteracy and information gap to identify risks and benefit of home delivery were among reasons of low skilled birth attendance. Majority of the participants were no one had interest to attend their delivery in health facilities unless complication faced. 
"Institutional delivery is the last option for us... we can manage everything without any challenges using our traditional birth attendants." (FGD_3 Participant)

\section{Category-2: Low risk perception to pregnancy and delivery}

"...in my life I know one woman who gave birth in her home more than 12 times without any health risks or complications. So, why you forced us to go and give birth in health facility. As you observed; there is no road, transport and is very difficult to reach to nearby health facility due to flooding, filled river and mud." (FGD_3 Participant)

\section{Theme-2: Community reasons of home delivery}

\section{Category-1: Women's poor position to decision}

Majority of health care providers said that husbands are considered influential in deciding the whole process at home and dependency on husbands' financial support is one of the reason for poor provision of skilled care during pregnancy and delivery.

"... Only we husband have power in deciding where wives should give birth. This is due to fear of payment and not to miss the deceased women in the referral hospital since majority of people believed many hospitals use the deceased body for teaching learning process..." (FGD_1 Participant)

\section{Category-2: Beliefs and cultural practises at home delivery}

\section{During birth}

Religious acts conducted during childbirth were among reasons to retain labouring women in home.

"During home delivery, prayers of priests come and conduct religious practices, reading religious books entitled with 'Metsehafe Rufaele' and 'Abune Zeraberuk'e. With by nodding his head and souk up his lip we highly believed on these religious books to be read during labouring time because of immediate solutions." (FGD_1 Participant)

All FGD participants believed that spiritual books have power to ease and facilitate labor.

"For me, if these books are available in my home during my labor, no need of going to health facility." (FGD_3 Participant)

"If labor is prolonged, we will conduct various traditional practises such as females roast coffee; if the women do not yet deliver, men would then substitute the women and roast coffee to consider their luck." (FGD_1 Participant)

"In my life, I confronted one woman whose labour endured three days. However, when I started roasting coffee, she delivered immediately. Hence, many individuals want me to roast coffee when their wives started have labour by considering me as the luckiest person and all Laughed." (FGD_1 participant) 
"If the first trial were failed, other options will be attempted. For instance, Fenugreek in local language, "Abash" will take the place of coffee to be roasted. "Fenugreek roasting" believed to be a tool to acquire St. Mary come and to be blessed the labor process. They all understood that, labor would facilitate and smooth with the help of St. Mary." (FGD_3 Participant)

"...There is a habit of putting husband's trousers under the pillow and sleep on it to facilitate delivery." (FGD_3 Participant)

"Besides, extra amazing traditions were conducted if labor is welcomed. Both men and women were forced to untie their belts; all closed household containers were open. If possible a selected sheep could be bought from anywhere and rounded three times on the head of the laboring mother, then the sheep will stand or slaughtering in front of the laboring mother to make excite and give birth immediately." (FGD_3 Participant)

\section{After birth}

All participants mentioned that when women faced lost her consciousness after delivery/in local language 'Sereka', they immerse in a river to make her conscious. Besides, poorly had a habit of putting Maria Teresa in between the victim upper and lower teeth to prevent clinch and sometimes people made postnatal mothers to catch mirror in front of her face to prevent eye closure.

All participants said that in addition if the postnatal mother loses her consciousness, we start knocking tin, whipping whip, installing spear parallel to the pillar of the house to prevent entrance of 'Sereka' and firing gun near her ear to make her wake up so far nowadays there is improvement. All religious leaders believed that they had traditional medicine to remove retained placenta.

"...When retained placenta is faced, the woman sits on hyena's leather and on dry cow dug by the tip of her legs...then the placenta could be removed soon..." (FGD_3 Participant and FGD_2 participant)

They also claimed that local language 'Adefe/yhuala leje' or retained placenta could be remove if a script from 'Melke Rufaele' or religious book is read. If such acts could not remove the retained placenta, the traditional healers can prepare local medicines from different herbs. Most of the participants said that, 'the placenta is buried inside home because the community is considered it as second child.

All FGD participants said that If it is throwaway home, the women might be suffering from severe abdominal pain called as local name "Marate". So, the placenta should be buried inside home by the husband's left hand using spear. Most respondents knew that laboring women do not allow go out of home before the baby is baptized with holy water which is supposed to protect them from evil or devil spirit and because of fear of crossing the river brings heavy snow and rain to inhabitants. 


\section{Theme-3: Health Facility Related Barriers}

\section{Category-1: Lack of availability}

"...in our health Centre, there is no water and light. You can imagine without water how could we manage laboring women and with no light most investigations can't be done and sterilization is difficult for delivery sets." (KI-1 participant)

In addition to this all healthcare providers worry about patients or client health due to shortage of basic needs of the health facility.

"...to your surprise in our health facility, by nodding his head, there is no delivery coach and other important delivery equipment. We simply help our mothers on antenatal coach, which is broken. Government declared that no woman could die while she gives life but this motto doesn't work for those marginalized women." (KI-1 participant)

\section{Category-2: Issues related with access}

Most HCP and HEWs explained, the long and difficult journey to reach the nearest health centre with no adequate infrastructure to use institutional delivery.

"...Maternal death will be continuing in rural Ethiopia unless problems linked to health facilities are not averted." (KI-1 participant)

"The problem was worsening during winter since most deliveries could happen at night that makes difficult to carry labouring mother reaches health facilities". (KI-2 participant)

"...Due to infrastructure, topography and other barriers, they are still doing nothing to save lives. Due to this, most of laboring women said that our home had better care than health facilities". (KI-1 participant)

\section{Category-3: Lack of privacy}

The health extension workers indicated that, lack of privacy at health facility during delivery is one of the reasons for home delivery.

"Most of the time we prefer to deliver in home than health institution. This is because of not exposing our bodies to an outsider including students that touches repeatedly for learning-teaching process. But, in our home no one can touch us except female family members." (FGD_3 Participant)

\section{Category-4: Misconducts of health providers'}

Most participants revealed that, health providers are generally criticized, distrusted and not accepted by their approaches. They usually serve by focusing on urban dwellers and relatives. 
"... When we visit health facility in some occasion, health providers do not say welcome and give attention to us. We see them simply quarrel, disrespect for us and they considered themselves as 'God." (FGD_1 Participant)

\section{Category-5: High risk perception to health facility delivery}

Most participants perceived that risks towards institutional delivery. During institutional delivery, we worry about further referrals, our uterus not to be tied, not to be exchanged their new-borns, exposure of babies' eyes to excessive light. Most participants also complained about risks of pelvic examination.

"Ohm ... I hate medical students as they are the beginner for everything I worry about the health of my uterus and foetus, the eyes of my new-born baby and I worry not be contaminated with infectious disease during vaginal examination." (FGD_3 Participant)

"There were many health risks occurred in the new-born baby during pelvic examination and delivery in her lives. Of these in her life, she saw one baby injured by fingers of health care provider during inserting her hand in her vagina, as his eye was red for a long period of time". (KI-3 participant)

\section{Category-6: Community's misconception towards health facility}

Majority of participants had misconceptions towards health facility delivery. If the baby nose is broad and short and the forehead is protruded, the communities think that the existence of such body structure is due to healthcare provider mistakes.

"...in home delivery we can assist manually the structure of newly born babies nose straight by pinching and pulling up and prevent the forehead from frontal bossing through squeezing around the head soon or before the bone gets hard". (FGD_3 Participant)

\section{Discussion}

According to the current study, health facility was not first option for delivery as they consider themselves low risks to pregnancy and delivery. This is highly consistent with research conducted in different low and middle income countries [16, 19-22]. This might be due to knowledge gaps to recognize pregnancy and delivery related danger signs and symptoms.

Women's poor position to decision is one contributing factor for not using institutional delivery. Beliefs and cultural practices at home delivery affects institutional delivery. In addition, health facility related barriers like inaccessibility of health facility, lack of privacy during delivery, misconducts of health care providers and high risk perception to health facility delivery were raised as reasons of last option of institutional delivery. This might have implicated that there is gap in implementing health promotion strategies that are applied practically to anticipate the importance of institutional delivery and risk of home childbirth. This could be addressed in antenatal follow-up which was effective occasion in enhancing the use of trained delivery attendants during parturition. 
This study showed that majority of mothers didn't consider institutional delivery, unless they faced complication during labor and they like the naturalness of home delivery rather than institutional delivery.

This is recognized for all the community people with which they were deeply embedded with sociocultural problems and misconceptions as these findings supported by other studies as well. [18, 23].

Consist with previous studies $[2,3,18,20]$, our finding indicted that most ladies lack decision making power in paying to household materials, maternal health looking for. The problems are not only for the Ethiopians, but for the majority of low and middle income countries that education is unaddressed equally and adequately.

This study showed that husbands are the decision makers for selecting place of delivery. Husbands believed that labouring mums should be giving birth in their home as previous experienced mothers can manage every problem. The wide prevalent control of economy of the household by husbands' may also contribute for home delivery.

Our findings comparable to various studies $[3,7,16,24]$, Beliefs and misconceptions were another nontouched community related barriers that hold back mothers in house during delivery. Besides, similar with other few studies, postnatal mothers forbidden and protected in home until baby baptism and the placenta is not thrown away home. In addition to this result, many religious acts conducted during and after delivery such as, preparing porridge, massaging the labouring abdomen with Fenugreek dough and performing homemade ceremony were among concealed reasons lack safe care during labor $[17,25]$.

Similar with least and middle income countries $[6,15,18]$ this study district mothers of Ethiopia had been still challenging on benefits of modern health facility delivery. Among challenges were issues related with availability and distribution of modern health facility with its communications. Modern health facility is a type of facility where basic essential obstetric cares are provided; infrastructures including with skilled workers equipped[15]. As shown in study setting, in the study district only seven health centres were available and planned to give services for estimated, 221,798 inhabitants[6]. One health centre established to serve four to five Keeble's. In these Keeble estimated, 5, 000 dwellers were resided. Of the total health centres, only two health centres were modern health centres found in urban comparatively adequate infrastructure. The remaining five health centres found in five clusters were highly marginalized in all rounds and located at least $20 \mathrm{~km}$ at most $70 \mathrm{~km}$ far from the capital of the district was Gemjabet.

Moreover, the Ankasha Guagussa district was extremely disadvantageous in means of transportation, distributions of health institutions and infrastructure similar with study done in different countries. In general, all villages are connected to health posts and modern facilities only by footpaths. Achieving any kind of facility was a challenge, and this had a contradictory effect on the user and provider of health services $[18,26]$.

This result is in line with the previous studies $[7,16,17]$ as scatter population settlement contribute to long distance to reach to nearby health centre. There is also a long distance to referral hospitals. In 
addition, health providers' competency issued by the community, unavailability of infrastructure and ambulance service are highly contributors for home delivery preference.

Another notable finding in the study was that lack of privacy play a prominent role in home delivery preference. This is because of fear of exposing their bodies to the outsider even they did not want to be touched with their respected husbands' as this finding is supported by other studies. [18, 27, 28].

\section{Conclusion And Recommendations}

Home delivery preference was existing in the study setting. High socio-cultural value and misconceptions towards health facility delivery, knowledge gap, distrust, need privacy, poor women's decision, infrastructure and financial constraints were reported as main contributing factors for institutional delivery. Thus, efforts should be made to resolve the low institutional delivery by considering the above main contributing factors.

\section{Declarations}

\section{Competing interests}

The authors declared that they have no conflicts of interest

\section{Abbreviations}

EDHS: Ethiopian Demographic Health Survey; FGDs: Focus Group Discussions; KI: Key informant interview

\section{Acknowledgements}

Our special gratitude goes to the local community participants, heads of health facilities and all staff members for their unlimited support and provision of the required information and Gates Institute at Johns Hopkins University for financial help during data collection.

\section{References}

1. ETHIOPIA Demographic and Health Survey 2016 Central Statistical Agency Addis Ababa, Ethiopia The DHS Program ICF Rockville, Maryland, USA July 2017

2. UNAIDS: Report on the global AIDS epidemic. Geneva, Switzerland: UNAIDS; . 2009.

3. Nwokeukwu HI OP, Okorie O, Ukpabi IK: Pediatric HIV and treatment of children living with HIV. http://www.who.int/ HIV/topics/paediatric/en/index.html.

4. WHO U, UNICEF: : Towards universal access: Scaling up priority HIV/AIDS interventions in the health sector. Progress report 2010. Geneva, Switzerland: WHO; 2010. 2010.

5. Hogan MC. et al. Maternal mortality for 181 countries asaoptmdgLd. 
6. Mulunesh A. WM: The Prevalence of Skilled Birth Attendant Utilization and Its Correlates in North West Ethiopia Hindawi Publishing Corporation BioMed Research International Volume 2015, Article ID 436938, 8 pages http://dxdoiorg/101155/2015/436938 2015.

7. Gurmesa Tura AGM: Safe delivery utilization in Metkel zone, North West Ethiopia Ethiopian Science Journal of Public Health 2013; 1(1):18-23.

8. Isaakidis P PR, Khan S, Mansoor H, Manglani M, Valiyakath A, et al: Poor outcomes in a cohort of HIV-infected adolescents undergoing treatment for multidrug-resistant tuberculosis in Mumbai, India. PLoS ONE. 2013;8(7):e68869. PubMed PMID: 23894358. Pubmed Central PMCID: 3716893. Epub 2013/07/31. eng. 2013.

9. Ethiopia Demographic and Health Survey 2011. Addis Ababa, Ethiopia and Calverton, Maryland, USA. Central Statistical Agency [Ethiopia] and ORC Macro: 2012. 2011.

10. Hesseling AC WA, Werschkull H, Donald P, Beyers N, Hussey G, El-Sadr W, Schaaf HS: Outcome of HIV infected children with culture confirmed tuberculosis. Archives of disease in childhood 2005, 90(11):1171-1174. 2005.

11. Ethiopia Demographic and Health Survey 2000; Addis Ababa EaC, Maryland, USA. Central Statistical Authority [Ethiopia] and ORC Macro: 2001.: 2000.

12. Ethiopia Demographic and Health Survey 2005. Addis Ababa EaC, Maryland, USA:. Central Statistical Agency [Ethiopia] and ORC Macro. 2006.: 2005.

13. Ethiopia Demographic and Health Survey 2011. Addis Ababa EaC, Maryland, USA. Central Statistical Agency [Ethiopia] and ORC Macro: 2012: 2011.

14. Rose NM MpembeniEmail author JZK, Melkzedeck T Leshabari, Siriel N Massawe, Albrecht Jahn, Declare Mushi and Hassan Mwakipa: Use pattern of maternal health services and determinants of skilled care during delivery in Southern Tanzania: implications for achievement of MDG-5 targets BMC Pregnancy and Childbirth20077:29 https://doiorg/101186/1471-2393-7-29.

15. Munabi-Babigumira S GC, Lewin S,Fretheim A, Nabudere H: Factors that influence the provision of intrapartum and postnatal care by skilled birth attendants in low- and middle-income countries: a qualitative evidence synthesis. CochraneDatabaseof SystematicReviews 2017, Issue 11. Art.No.: CD011558. DOI: 10.1002/14651858.CD011558.pub2. www.cochranelibrary.com. .

16. Øxnevad M: Perceptions and practices related to home based and facility based birth. A qualitative study from Agemssa, Ethiopia. Centre for International Health Faculty of Medicine and Dentistry University of Bergen, Norway, 2011.

17. Sarker SRH-E-NMA: Factors Influencing Utilization of Manoshi Delivery Centres in Urban Slums of Dhaka. BRAC Research Report BRAC Centre, 75 Mohakhali, Dhaka 1212, Bangladesh Web: www.bracresearch.org December 2009.

18. Meselech Assegeid Roro*1 EMH, Alemayehu Mekonnen Lema1, Seyefu Hagos Gebreyesus1 and Mesganaw Fenathun Afework1: Why do women deliver in health facilities: a qualitative study of the community perspectives' in south central Ethiopia? Roro et al BMC Research Notes 2014, 7:556 http://wwwbiomedcentralcom/1756-0500/7/556. 
19. Angelshaug J: Increasing demand for health facility birth: A qualitative study exploring barriers and facilitators for skilled care utilization in the Amhara Region, Ethiopia Centre for International Health Department for Global Public Health and Primary Care Faculty of Medicine and Dentistry University of Bergen, Norway 2013.

20. Van Rie A BN, Gie RP, Kunneke M, Zietsman L, Donald PR Childhood tuberculosis in an urban population in South Africa: burden and risk factor. Arch Dis Child 1999; 80: 433-437. 1999.

21. Kabra SK LR, Seth V Some current concepts on childhood tuberculosis. Indian J Med Res 2004; 120: 387-397.1992. 2004.

22. Eyobe Zera el: Inequities in skilled attendance at birth in Namibia: A decomposition Analysis

23. Mushi D, Mpembeni, R., Jahn, A: Effectiveness of community based safemotherhood promoters in improving the utilization of obstetric care. The case of Mtwara Rural District in Tanzania. BMC Pregnancy and Childbirth 2010, 10:14. 2010.

24. Federal Democratic Republic of Ethiopia MoH NRHS-.

25. Zere E, Oluwole, D., Kirigia, J., Mwikisa, $C$ and Mbeeli, $T$ Inequities in skilled attendance at birth in Namibia: A decomposition analysis. BMC Pregnancy and Childbirth 2011, 11:34. 2011.

26. Pillay T1 KM, Moodley J, Adhikari M, Padayatchi N, Naicker V, Pillay DG, Coovadia HM: The increasing burden of tuberculosis in pregnant women, newborns and infants under 6 months of age in Durban, KwaZulu-Natal. S Afr Med J 2001 Nov;91(11):983-7.

27. Rose NM M J e: Use pattern of maternal health services and determinants of skilled care during delivery in Southern Tanzania: implications for achievement of MDG-5 target BMC Pregnancy and Childbirth 2007, 7(29).

28. Teferra e a: Institutional delivery service utilization and associated factors Among Mothers who gave birth in the last 12 months in Sekela District, North West of Ethiopia: A Community - based cross sectional study. BMC Pregnancy and Childbirth [internet] 2012, Available from http://wwwbiomedcentralcom/1471. 2011

\section{Tables}

Table 1: Basic Profile of Focus Group Discussants of Ankasha Guagussa, 2014 


\begin{tabular}{|c|c|c|c|c|}
\hline \multicolumn{2}{|c|}{ Characteristics } & $\begin{array}{l}\text { Female } \\
(n=12)\end{array}$ & $\begin{array}{l}\text { Religious Leaders } \\
(\mathrm{n}=10)\end{array}$ & $\begin{array}{l}\text { Community Leader } \\
(\mathrm{n}=12)\end{array}$ \\
\hline \multirow[t]{3}{*}{ Age in years } & $20-34$ & 5 & 0 & 2 \\
\hline & $35-44$ & 7 & 4 & 5 \\
\hline & 45 above & 0 & 6 & 5 \\
\hline Sex & & Female & Male & Male \\
\hline \multirow[t]{3}{*}{ Marital status } & Married & 10 & 10 & 12 \\
\hline & Divorced & 1 & 0 & 0 \\
\hline & Widowed & 1 & 0 & 0 \\
\hline \multirow[t]{4}{*}{ Number of children } & Null & 0 & 0 & 0 \\
\hline & $1-2$ & 1 & 0 & 2 \\
\hline & $3-5$ & 6 & 1 & 4 \\
\hline & 6 above & 5 & 9 & 6 \\
\hline \multirow[t]{5}{*}{ Educational status } & Illiterate & 8 & 0 & 0 \\
\hline & Read and write & 2 & 9 & 4 \\
\hline & Some primary (1-4) & 1 & 0 & 6 \\
\hline & primary(5-7) & 1 & 1 & 1 \\
\hline & Tertiary & 0 & 0 & 1 \\
\hline Occupation & Farmer & 10 & 12 & 12 \\
\hline
\end{tabular}

Table 2: Basic Profile of Key In-Depth Interviewees of Ankasha Guagussa District, 2014 
Health Care Providers Health Extension Informal participants $(\mathrm{HCP})(\mathrm{n}=4)$

Characteristics

$(\mathrm{n}=6)$

\begin{tabular}{lllll} 
Age in years & $20-34$ & 3 & 5 & 6 \\
& $35-44$ & 1 & 1 & 0 \\
Mean=29 & & Mean age=28.8 & Mean age $=29.2$ & Range $=29.2$ \\
Range=24-38 & & Range =24-38 & Range 23-35 & Range $=24-34$ \\
\hline Sex & M & Male & Female & Female \\
& F & & & 0 \\
Marital status & Single & 2 & 3 & 6 \\
& Married & 2 & 3 & 0 \\
\# of children & Null & 3 & 4 & 1 \\
& $1-2$ & 1 & 2 & 5
\end{tabular}

$\begin{array}{lllll}\text { Educational } & \text { Illiterate } & 0 & 0 & 4 \\ \text { status } & \text { Read and write } & 0 & 0 & 2 \\ & \text { Tertiary } & 4 & 6 & 0 \\ \text { Occupation } & \text { Farmer } & 0 & 0 & 6 \\ & \text { Employed } & 4 & 6 & 0\end{array}$

